\title{
Clubbing in the Afternoon: Worlding the City as a College-Girl in Chennai
}

\author{
Highlights
}

- With rising cultural nationalisms, young women in urban India find themselves under increasing surveillance.

- This restricts their access to cultural forms that constitute 'youth culture' in Indian cities.

- Ethnography in Chennai shows that a burgeoning culture of Afternoon Clubs allows young women to subvert this temporal discipline.

- In analysing this, the paper brings insights from non-representational theory to bear on subculture scholarship.

- It shows that Afternoon Clubs reorient young women's urban experience away from vulnerability.

\section{Introduction}

As we left the restaurant where I'd been interviewing her one afternoon in Chennai, nineteenyear-old Deepa turned to me and said: 'Oh, and I'm going clubbing for my birthday. Come.' Deepa lived at Theresa Ladies' Hostel, a residence hall for women students in the city. The hostel had a strict six pm curfew: a rule that usually meant that students could not make plans for the evening. The most they were allowed was to order in food instead of eating in the dining hall. And even that required permission. But Deepa wasn't planning on going clubbing in the evening. Her birthday party was at one of Chennai's many new Afternoon Clubs: commercial establishments and private gatherings that create 'nightlife' during the day for youth in a city where anxieties about sexual violence and urban danger have resulted in a range of restrictions that prevent young women from accessing the city in the evening.

This paper draws on ethnographic research to examine cultures of afternoon partying among young people in Chennai. Youth in India are at the heart of a post-1990 culture of consumption and leisure in urban spaces in which a popular discourse of gendered 'risk' ambiguously indexes both the danger of sexual violence, and social anxieties about young women transgressing caste and class boundaries (Parikh, 2017; Bernroider, 2018; Chakraborty et al., 2017). The college-going women with whom I conducted fieldwork found their access 
to the city and its potentials heavily regulated: most prominently by curfews in their student residences that prevented them from going out after six pm. In this context, afternoon parties and clubs - events that simulate the ambience of nightclubs, albeit in the daytime - allow young women to experience clubbing and urban nightlife, without actually having to be out at night.

In unpacking this phenomenon, in this paper I advance a reading of urban worlding drawn from queer theory to examine how the city is assembled in young women's experience of it: as unsafe and a site of surveillance on the one hand, and as a place of pleasure, transgression and potential in their participation in afternoon clubbing cultures. 'Worlding' has been increasingly studied as a theoretical lens through which to unsettle the regional fixity of urban studies. Coming from a critique of the grand narratives that undergird dominant Marxist and postcolonial framings of the urban as a site of class struggle, Ong (2011) and Roy (2011) have variously drawn on assemblage theory in geography to posit the urban instead as simultaneously local and global, and always contingent and in process. McCann et al (2013) posit three different models of worlding in the study of the urban: first, worlding as a site of intervention in which cities are materialized using 'parts of elsewhere' as scalar assemblages; second, worlding as being cast out into the world through circuits of migration and capital flow; and finally, worlding as related to the Heideggerian 'worldview': i.e. as an experiential practice of knowing the city. While these framings are critical, this paper builds beyond them to ask deploys queer theory's focus on worlding as embodied to unpack an urban sensory assemblage that unsettles both regional fixity and temporal order.

In her work on space and precarity, Kathleen Stewart (2011: 445) writes about worlding as a 'compositional process of dwelling in spaces that bears, gestures, gestates, worlds'. Building on this conceptualisation, I unpack 'worlding' as a processual and experiential mode in which the city is materialized as an affective assemblage. The case of young women's experience in afternoon clubs allows this paper to ask in particular how 'worlding' in this mode 
allows subcultural forms to emerge. The turn to non-representational methods in human geography has precipitated thinking on atmospheres that critically unpacks 'the diffuse, collective nature of affective life' (Anderson and Ash, 2015: 34) beyond emotion. In examining afternoon clubs as a kind of 'worlding' in this sense, I bring Geography's non-representational turn to bear on an older debate about youth and cultural resistance (Hall and Jefferson, 2006; Hebdige, 2013). In doing so, this paper asks how embodied stylistic forms, linguistic registers and sensory ecologies cohere in some contexts into distinct forms that we might call 'subculture'. The subculture scholarship has been re-engaged recently by a new scholarship in urban geography that seeks to unpack the spatiality and scalar networks of creativity that engage cities as sites of cultural production (Charrieras et al., 2018; Cretella and Buenger, 2016; Mattson, 2015). Unsettling developmental logics and imaginaries of futurity that undergird the making of normative cultural life, feminist social theorists and geographers simultaneously ask how subcultural potentials might be evoked in queer inhabitations of cities (Oswin, 2015; Halberstam, 2011; Binnie, 2014): 'worldings' that orient the body differently to objects of desire and happiness (Ahmed, 2010). In these readings, 'subculture' disrupts the nostalgia and continuity associated with national community embodied in the discourse of the biological family (Drysdale, 2018; Oswin, 2014) by emphasising 'transient, extrafamilial and oppositional modes of affiliation'(Halberstam, 2011: 315).

The lens of 'worlding' as compositional process allows this paper to see subcultures as processes of dwelling, rather than as fixed sites of cultural production Here, urban landscapes are produced within contingent moments of re-articulation: creating atmospheres and sensory spaces of resistance that disrupt the normative ordering of space and time. Participation in afternoon parties and clubbing culture allows young women in this city to unsettle their iteration as vulnerable subjects of urban danger, through a simulated 'nightlife' that disrupts the temporal order imposed by curfews. In the sections that follow, I begin by first laying out 
the context and methods for this study, before developing arguments on young women's urban worlding through afternoon-clubbing subcultures.

\section{Gender and Youth in Chennai: Introducing the Afternoon Club}

Youth in India have been widely studied in the context of the socio-political transformations that have swept the region since the mid-1980s. As in contexts elsewhere in the world (Newell, 2012), scholars have shown that youth do not simply reproduce 'Western' cultural forms but instead articulate their position within locally-rooted contexts (Nakassis, 2016). While they have not been studied as subcultures, scholars have pointed out that 'style' is increasingly integral to what it means to be 'young' (Nakassis, 2016). Simultaneously, caste and communal boundaries have come to be policed with growing brutality: a violence that is writ particularly on the bodies of young women (Shandilya, 2015; Srinivasan, 2016; Brosius, 2011). In this context, scholars note that the Indian middle-classes have receded behind gated and securitized spaces: gendered and sexualized bodies in particular become 'risky' border-zones of policing (Patel, 2017a), and sites where contestations over urban and geopolitical space is enacted (Dupont, 2016). Particularly in the wake of the widely-reported rape and murder of a college student in New Delhi in December 2012, the young women I met found that their families and educational institutions clamped down on regulations ostensibly intended to keep them safe, but which also severely restrict their mobility and ability to participate in a 'youth culture' (Patel, 2017b).

Women's hostels - dormitory-style accommodations where university students live where my work has been mainly based, have responded by enforcing regulations that are ostensibly intended to keep young women 'safe' but also regulate their mobility and access to urban publics, thus preserving respectability. In this, hostels play a significant role in the spatial construction of respectability in Indian cities: an issue that a New Delhi- based movement spear-headed by college-students has foregrounded in its demand to end hostel curfews (Roy, 
2016). Founded from the late $19^{\text {th }}$ century onward, hostels for women have long been sites for the making of gendered middle-class subjectivities in Indian cities. They might thus be read as sites where technologies of the self (Foucault, 1990) are mobilized to inculcate self-discipline in young women. In Chennai, where I did fieldwork, curfews were as early as four pm for firstyear students and never later than seven pm. Hostels also enforced a range of regulations against young women visiting establishments that might mark them as lacking in respectability: for instance, bars and clubs in the city, as well as concert venues with the exception of classical music halls. Indeed, a popular music video released by a Tamil Hip-hop group in 2012 reinforced the male gendering of youth cultures centred on partying, consumption and 'hanging out' in urban publics. In this song, a young Tamil man dressed stylishly in jeans and a jacket, as well as sunglasses sings about the 'kind of women who go to clubs'. He argues that Tamil men run for shame at the sight of such women, who 'reject the sari and wear handkerchiefs instead.'

Within a wider geographical scholarship, scholars draw on the 'right to the city' framework to interpret the strategies that women and marginalized communities use to subvert their being 'put in place' by normative frameworks (Vacchelli and Kofman, 2018; Hancock et al., 2018). In this scholarship and beyond, it is evident that women subvert the claims that communities make on their bodies through creative practices that allow them to participate in 'youth cultures', practices of friendship and homosociality and professional lives (Harb and Deeb, 2013; Masood, 2018; Şahin, 2018). Such practices entail forms of disruption that are not necessarily paradigm-shifting or generative of lasting transformations, even as they unsettle power structures.

Afternoon clubs - many of which are located in malls and major shopping districts in the city - are indicative of the emerging political economy that brings together young women's practices of consumption with the demands of respectability among an increasingly anxious 
middle-class. Some afternoon parties occur at private homes and are not commercial, even though large groups attend these events, often including many who are not directly connected with those who host them. The hosts of these parties tend to be students who are in the unusual situation of living alone or with roommates in a flat sans parental supervision. In these circumstances, young people gather in large numbers in these homes: dancing and partying until about six pm, when other families in the neighbourhood begin returning home and hostel curfews begin. These gatherings - both commercial and private - are quite popular and tend to be attended most widely by college-going and middle-class youth in the city. During my fieldwork period, they were seen as an important site for after-class socializing among students across colleges in the city.

The potential for interstitial transgression in these Afternoon Clubs is located both in their temporal innocuousness, as well as in their status as commercial or private spaces that exclude many of those who are typically seen as posing 'risk' to young women's safety. The afternoon time was widely seen as a period of leisure. Parents typically did not expect their daughters back home until after this time, and hostel curfews began at the earliest time of halfpast-four. While being out in the evening was associated with disrepute, young women felt 'safe' being out during the day: at worst, if things went wrong at the club, it was still daylight and getting home would be an easy business. Simultaneously, afternoon clubs and parties were also policed spaces that excluded those who either could not pay the entry charges, or did not know the hosts of the party in question. This made them unquestionably middle-class in character, thus excluding subaltern men, who are typically stigmatized as dangerous to young middle-class women (Author 2016). So, on the one hand, this paper shows that young women do engage in creative practices to access the forms of consumption and leisure typically associated with young men (Rogers, 2008; Nakassis, 2016; Nisbett, 2007). On the other hand, such 'risky' pleasures are only enabled within privatized and enclosed spaces. In unpacking 
young women's participation in afternoon clubs, I argue that they enact every day and interstitial forms of subversion - disruptive modes of inhabitation that do not necessarily disrupt the making of normative life, but instead flourish in its incommensurabilities - that reorient their inhabitation of the city.

It is this paper's contention that this reorientation is the site of 'worlding': where the urban as a contingent assemblage is brought into being through young women's sensory experience of the afternoon club. Subcultures, in this reading, come together in processual modes, inhabiting interstices that open up potentials for disrupting the normative ordering of everyday life. In arguing that they 'world' the city into being, I suggest that they articulate a particular orientation towards the urban: here, allowing young women to experience the city as a site of pleasure and potential, as well as to participate in 'youth cultures' centred on hanging out and non-productive uses of time.

\section{Subculture as Assemblage: Worlding the City}

Geographers of urban subcultures have emphasized a focus on particular sites that subcultures come to claim (Homan, 2014; Mattson, 2015; Sheridan, 2007). In Chennai, and other Indian cities too youth stake out territory in various ways: most prominently by loitering and posturing on footpaths and near bus-stops, as well as by claiming public spaces such as urban parks and the beach as sites of flirtation. However, such public practices centre on visibility and are thus heavily gendered: a problematic noted both in historical and contemporary studies of gender and youth space in urban India (Sharma, 2016; Aengst, 2014; Patel, 2017b). As I have shown above, young women typically do not have access to them.

As frequent visitors of afternoon clubs - establishments that were located both in 'safe' and indoor spaces, as well as being active in the 'safe' hours of the daytime - young women did not see the space of the club as their only site of their subversion. Rather, the experience of clubbing in the afternoon reshaped their experience of inhabiting the city: allowing them to 
experience their bodies not as vulnerable but as subversively 'fun' and enjoyably capable of taking risks. In this view, subcultures do not so much carve out distinct territories within cities but instead re-world the city through an affective experience that reorients the subject in the city. In this, the paper rethinks subcultures not as distinct counter-cultural zones in urban spaces but as aesthetic and affective orientations through which subjects experience the city differently: inhabiting it through a counter-cultural lens. One of the young women I met likened the experience of Afternoon Clubbing and the 'sense' it left her with, to seeing the world through a different filter on her smart phone camera. The material and sensory assemblage of the subcultural site, here acts on the urban: rearticulating its potential.

The afternoon club as a subcultural site had its boundaries: sensory sites that marked potential shifts in the affective experience of the city, and in embodied ways of inhabiting it. How do you know you're at the right place? The smell should tell you, that's how. This was the first piece of advice I got before my first visit to an afternoon club. And indeed, the boundary-zones of afternoon clubs were marked with the smell of marijuana: a sign, as one of my informants saw it, that we were crossing into a different time. We would be no longer in daylight: in the time of good girls, of the transparency and moral clarity associated with the glare of the sun. This sensory boundary is a good example of the way in which young women spoke of Afternoon Clubs and how they shaped their perception of the city. The first club I went to was a small establishment that did not serve alcohol but was located in an area that college-students knew to be dense with 'other things'. And indeed, with the crowd of smokers standing just outside the club, the threshold was a sensory boundary: thick with the potential for 'something to happen' as a nineteen-year-old who took me to the club put it.

Inside, the club was a darkened space with English-language pop music playing: not very different from the many nightclubs that have opened in Chennai in the past few years. A group of young men and women in school uniforms, suggesting that they were high-school 
students, stood around near the bar that was serving mocktails. Others danced or sat around. A few couples sat in intimate embraces or kissed in the darker corners of the room. 'The feel' of the club, as many informants often called it, was that of night-time: the throb of the music, its loudness, the sense of intoxicated leisure all suggested leisure hours after the workday. But that was not the only thing the women I was here with had come for. Most of them had dressed in modest dress-code approved clothing for their morning classes at College and now, they pulled off layers to reveal strappy tops, plunging necklines and short skirts. We trooped into the bathroom for make-up and the women I had come with put on copious layers of eye shadow and lipstick: 'an evening look' as one of them put it, for a club that simulated the night-time. They laughed, pouted and took selfies, standing around and posturing in ways that most of them did not feel they could in public spaces. The afternoon club was a place where young women participated in the practices of visibility that is available to young men in public spaces.

The club also came into coherence as a subcultural site in the encounters that it facilitated in its atmosphere of music, and the alignment of bodies and comportments it facilitated: inviting young women to 'lose it' and 'just be mad' and dance. Contrary to the distance with which young women held themselves in relation to young men in public spaces, the afternoon club facilitated erotic potentials, and experimentation. In this, it subverted the regime of curfews, walls and security cameras that sought precisely to forestall such possibilities. Shahana, a young woman who lived at Theresa Hostel often went to a private afternoon party at a nearby bar that was strictly afternoon-only and closed down after six pm. A devout Muslim, Shahana did not drink or smoke: she went to the club, she told me, 'for the feel'. The inside of the club was darkened and the lights were dim. The music was loud and Shahana said she felt anonymous, even invisible in the crowd there. She felt, she said, one with the music. 'I danced like a devil' she said gleefully one day, slowly unwinding her headscarf now that we were back in the hostel. In the club, Shahana said, she did not feel stared at as she 
did on the road, where young women often experience being ogled simply for their public presence. There, she could 'let go' and 'be loose' - the latter, to her, meant that she could let her limbs flail about as they might. The city, to Shahana, came alive in those moments: this was 'cosmopolitan Chennai' she said one day, making the comparison to the smaller city of Calicut in Kerala where she originally came from. Going to the afternoon club also shaped Shahana's social life: shared enjoyment of this space led her to a romantic relationship with a fellow club-goer. Shahana had been attracted to him when she saw that he too did not drink, but only came to the club for the 'mad feel': the sense of being able to let go.

The afternoon club as a subculture thus emerged within the context of urban potentiality and consisted of the coming together of the atmosphere of night-time, created by darkened interiors and loud music, as well as potentials for intimacy and relaxation that the movement of bodies in close proximity with each other allowed for. While Shahana had met her boyfriend at the club, another aspect that many young women enjoyed was that these parties and clubs were usually fuller of women than men: another inversion of the normal state of affairs at nightclubs in India. Many young women I met enjoyed dancing and inhabiting potentials for 'letting go' in the safety that this suggested to them. The afternoon clubs that the women I met attended allowed them to render fluid the boundaries of appropriate femininity. As they left clubs, young women transformed again into 'good girls', changing back into modest clothing, wiping off some of their make-up, and walking swiftly and purposefully without hanging about and lingering. Nevertheless, Darshana, whom I began this paper with told me, having gone to the club made her feel like she was carrying an exciting secret with her all day: even after she was sober again and in the hostel. Going to the club after college most days made Darshana's friend, Ritika feel like she knew the city: a sense she did not have before she began frequenting these gatherings. 'Knowing the city' suggested, to Ritika, intimacy with the space: something she felt the regime of curfews and regulations had not afforded her. 


\section{Temporal Subversion and Urban Youth Subcultures}

There a number of ways in which, the young women I met told me, they lived 'upside down lives' (tala-keezha). They slept in class and during lab hours, and stayed up all night in the hostel because that was the only time the warden was asleep and not watching them. They went to the beach in the scorching hours of the afternoon to have sex in the catamarans that the fishermen left out on the sand, because in the evening there were families and children on the beach, and there was no space to canoodle. Temporal and spatial forms of subversion are closely interlinked in such practices: avoiding surveillance requires young women to ironically locate practices of intimacy in the 'outside' spaces of beaches and parks. By the same token, they also engaged in these practices not during evening hours when their presence in such spaces would be seen as 'risky' but by hiding in plain sight: using the heat and brightness of the day as cover. Similarly, young women spoke of time as speedy in its normative form: it felt like it was hurtling forward at an alarming speed, towards inevitable and normative adulthood marked by nine-to-five employment and marriage. In living 'upside-down' lives in the hostel, they often felt as if they were pausing this fleeting time of youth and engaging in forms of subversion that would simply be no longer feasible once they were out of college.

Temporal discipline has been linked with 'growing up' and with development: the creation of normative cultures in general. Chrononormativity - the ordering of time - is a key site at which 'success' within neoliberal norms in produced. The middle-class dream of the good life is dependent on temporal regimes in which childhood and adulthood, as well as 'backward' and progressive are clearly separated, even as individual days are ordered by capitalist modes of production that associate particular activities with distinct times (McDowell, 2011; Patel, 2017a). Elizabeth Freeman, who coined this term argues chrononormativities are established through 'a mode of implantation, a technique by which institutional forces come to seem like somatic facts' (Freeman, 2010: 3). Calendars, schedules, 
timezones and clocks create naturalized rhythms that become integral to the disciplinary organization of everyday life. Queer theorists have focused on the ways in which some bodies 'fail' this test of temporal coherence and progressivity in the fragmented narratives they tell of themselves, in positing queerness as the disruption of chrononormativity (Halberstam, 2011; Ramberg, 2016; Andrucki and Kaplan, 2018).

Temporal discipline further plays a role in materializing spatial discipline in urban contexts (Oswin, 2014; Patrick, 2014; Bagheri, 2014). Urban studies scholars have long shown that the regulation of time in urban spaces is a central site where the urban is produced as a busy place, entangled with the productive time of contemporary capitalism (Edensor, 2000; Matos Wunderlich, 2008). This scholarship has been developed recently in the dialogue on urban political ecologies and digital infrastructures, asking how more-than-human agencies shape visibility, affective experiences of urban life and the experience of urban mobility (Brosius and Schilbach, 2016; Rose, 2017). It is in this context that loitering in urban spaces is iterated as a form of subversion in cities (van den Berg and Chevalier, 2018). In marking themselves as subversive and non-adult, young men in India (Nakassis, 2016) - as well as in other Global South contexts (Wafer, 2017) - deliberately 'waste time' and loiter. For young women, however, loitering carries the additional danger of marking them as lacking in respectability (Chakraborty et al., 2017; Brosius, 2017). Their access to a 'youth culture' is mediated thus by the additional burden placed on their bodies as sites of communal and national reproduction.

Afternoon clubbing cultures subvert this logic in their embrace of the 'upside-down' time and the 'waste' of time that my informants associated with their lives as youth. In spending their afternoons dancing, 'hanging out' at parties, young women laid claim to a distinct culture of 'youth' that has been associated with young men's 'timepass' or 'wasting time' (Jeffrey, 2010; Lukose, 2009). Many laughed about how they were often already drunk at the time at 
which drinking is assumed to begin: in the early evening hours. By night-time, they had usually had naps and coffee, as well as the compulsory dinner in the hostel dining hall and sobered up completely. Night-time was thus a period of alertness: many worked on projects for college, and others gathered around someone's computer to watch a film. Almost no one slept. Tellingly, they explained to me that do so would be a 'waste': if they were forced to be indoors during the night, then they might as well work then, and save the daytime for fun.

The urban coheres here in young women's 'upside-down' inhabitation of its cultures of leisure and consumption, as well as in their refusal of its rhythms of busy-ness and productivity. If worlding is a mode of 'attunement', clubbing subcultures allow young women to be attuned to a sense of 'upside-down time' that both marks their inhabitation in the city and indicates the limits of their access to it. Atmospheric attunements suggest shifts in intensity and in the tempo of everyday time (Anderson and Ash, 2015). In spending their afternoons clubbing, young women experienced the city's temporal rhythms in an order that challenges the normative construction that institutions like hostels that order time in their lives enact.

\section{Conclusion}

The refusal of normative futurity has long been central to the aesthetic resistance articulated by subcultures and queer theorists have drawn on and elaborated this aspect of subcultural life as key to contemporary thinking on these issues. Afternoon clubbing in Chennai is squarely located in many ways at the heart of normative middle-class consumption cultures. However, rather than walk the 'fine balance' (Gilbertson, 2014) of respectability that scholars have shown young women are normatively expected to do as consumers, the women I met use consumption as a mode through which to subvert the embodied discipline that is associated with the daytime, as well as expected of them as middle-class women. In its 'upside down' character and the lack of productivity this implied, afternoon clubbing was a means of 'wasting time'. While the young women I met do not entirely refuse normative middle-class futures, they trouble the 
disciplinary regimes within which such an imaginary. Afternoon clubbing also opens up social potentials in young women's lives that the regulations set by curfews typically intend to preempt and foreclose.

The Afternoon Club as a shifting site that traverses both commercial locations as well as private parties and impromptu gatherings allows this paper to also rethink the fixity of subcultural sites at urban margins and in places of abandonment. Rather, I have examined a subcultural formation as an assemblage that reorients the subject in the city: allowing young women to experience the risk, excitement and subversion associated with nightlife, albeit in the day. As contingent spaces, afternoon clubs are marked by sensory experience: for instance, the smell of marijuana that was in the air, the loud music, the feeling of bodies in close proximity, and of erotic potential. In this, the paper contributes to an emergent debate on subcultures not as communities of representative meaning but as sites where youth inhabit nonnormative potentials.

It also develops a queer debate on worlding cities within postcolonial and Global South contexts (Oswin, 2015; Batra, 2016). In this approach, queerness is operationalized as a method and conceptual lens that unsettles the temporality of urban order. Bringing the scholarship on subcultures in dialogue with this allows this paper to unpack the reorientation of the subject in space as a site of embodied and subversive articulation. The paper thus builds on the provocation of scholars like Aihwa Ong (2011) to consider urban worlding beyond Western and liberal paradigms, while also developing the debate on 'worlding' beyond the processes of scaling and 'global city' making that Ong, Roy and others have typically focused on. 'Worlding' as a process of composition is animated in this experience of subcultural life, as young women inhabit the city through an attunement to affect. In the upside-down-ness of time that the Afternoon Club inspires, the urban incites affects that invert the normative logics that mark night-time and places like bars and clubs as 'dangerous' in the lives of young women. 
Instead, young women spoke of the 'fizziness' they felt at such gatherings: there was 'excitement' and the urban came alive to them as a place of potential. 'Risk' in its appropriation within afternoon clubbing cultures was to be embraced, as integral to the potential pleasures of the urban.

\section{References}

Aengst J. (2014) Adolescent movements: Dating, elopements, and youth policing in Ladakh, India. Ethnos 79: 630-649.

Ahmed S. (2010) The Promise of Happiness, Durham, NC: Duke University Press.

Anderson B and Ash J. (2015) Atmospheric Methods. In: Vannini P (ed) NonRepresentational Methodologies: Re-Envisioning Research. London: Taylor \& Francis, $34-51$.

Andrucki MJ and Kaplan DJ. (2018) Trans objects: materializing queer time in US transmasculine homes. Gender, Place \& Culture: 1-18.

Bagheri N. (2014) Mapping women in Tehran's public spaces: a geo-visualization perspective. Gender, Place \& Culture 21: 1285-1301.

Batra K. (2016) Worlding Sexualities under Apartheid: From Gay Liberation to a Queer Afropolitanism. Postcolonial Studies 19: 37-52.

Bernroider L. (2018) Single female tenants in South Delhi - gender, class and morality in a globalizing city. Gender, Place \& Culture: 1-17.

Binnie J. (2014) Relational comparison, queer urbanism and worlding cities. Geography Compass 8: 590-599.

Brosius C. (2011) Love in the Age of Valentine and Pink Underwear: Media and Politics of Intimacy in South Asia. In: Brosius C and Wenzlhuemer R (eds) Transcultural Turbulences: Towards a Multi-Sited Reading of Image Flows. Heidelberg ; New York: Springer, 27-66. 
Brosius C. (2017) Regulating Access and Mobility of Single Women in a "World Class"-city: Gender and Inequality in Delhi, India. New York: Palgrave Macmillan US, 239-260. Brosius C and Schilbach T. (2016) Introduction: "Mind the Gap": Thinking about in-between spaces in Delhi and Shanghai. Mind the Gap: Thinking about in-between spaces in Delhi and Shanghai 7: 221-226.

Chakraborty S, Kumar S and Subramaniam M. (2017) Safe city: Analysis of services for gender-based violence in Bengaluru, India. International Sociology 32: 299-322.

Charrieras D, Darchen S and Sigler T. (2018) The shifting spaces of creativity in Hong Kong. 74: 134-141.

Cretella A and Buenger MS. (2016) Food as creative city politics in the city of Rotterdam. Current Research on Cities 51: 1-10.

Drysdale K. (2018) Intimate attunements: Everyday affect in Sydney's drag king scene. Sexualities 21: 640-656.

Dupont V. (2016) Secured residential enclaves in the Delhi region: Impact of indigenous and transnational models. Mind the Gap: Thinking about in-between spaces in Delhi and Shanghai 7: 227-236.

Edensor T. (2000) Walking in the British countryside: Reflexivity, embodied practices and ways to escape. Body \& Society 6: 81-106.

Foucault M. (1990) The history of sexuality: Pantheon Books.

Freeman E. (2010) Time Binds: Queer Temporalities, Queer Histories: Duke University Press.

Gilbertson A. (2014) A Fine Balance: Negotiating fashion and respectable femininity in middle-class Hyderabad, India. Modern Asian Studies 48: 120-158.

Halberstam J. (2011) The Queer Art of Failure: Duke University Press.

Hall S and Jefferson T. (2006) Resistance Through Rituals: Youth Subcultures in Post-War Britain: Taylor \& Francis. 
Hancock C, Blanchard S and Chapuis A. (2018) Banlieusard.e.s claiming a right to the City of Light: Gendered violence and spatial politics in Paris. 76: 23-28.

Harb M and Deeb L. (2013) Contesting urban modernity: Moral leisure in south Beirut. European Journal of Cultural Studies 16: 725-744.

Hebdige D. (2013) Subculture: Taylor \& Francis.

Homan S. (2014) Liveability and creativity: The case for Melbourne music precincts. Making Creative Spaces 5: 149-155.

Jeffrey C. (2010) Timepass: Youth, Class, and the politics of waiting in India, Stanford: Stanford University Press.

Lukose RA. (2009) Liberalization's children: Gender, Youth, and Consumer Citizenship in Globalizing India, Durham NC: Duke University Press.

Masood A. (2018) Negotiating mobility in gendered spaces: case of Pakistani women doctors. Gender, Place \& Culture 25: 188-206.

Matos Wunderlich F. (2008) Walking and Rhythmicity: Sensing Urban Space. Journal of Urban Design 13: 125-139.

Mattson G. (2015) Bar districts as subcultural amenities. Making Creative Spaces 6: 1-8.

McCann E, Roy A and Ward KJUG. (2013) Assembling/worlding cities. 34: 581-589.

McDowell A. (2011) Echoing Silence: Backwardness, Governmentality and Voice in Contemporary India. Journal of Asian and African Studies 47: 348-362.

Nakassis CV. (2016) Doing style: youth and mass mediation in South India, Chicago: The University of Chicago Press.

Newell S. (2012) The Modernity Bluff: crime, consumption, and citizenship in Côte d'Ivoire, Chicago: University of Chicago Press.

Nisbett N. (2007) Friendship, consumption, morality: practising identity, negotiating hierarchy in middle-class Bangalore. 13: 935-950. 
Ong A. (2011) Introduction: Worlding Cities or the Art of Being Global. In: Roy A and Ong A (eds) Worlding Cities: Asian Experiments and the Art of Being Global. Malden: Wiley, 1 - 26.

Oswin N. (2014) Queer time in global city Singapore: Neoliberal futures and the 'freedom to love'. Sexualities 17: 412-433.

Oswin N. (2015) World, city, queer. Antipode 47: 557-565.

Parikh A. (2017) Politics of presence: women's safety and respectability at night in Mumbai, India. Gender, Place \& Culture: 1-16.

Patel G. (2017a) Risky Bodies \& Techno-Intimacy: Reflections on Sexuality, Media, Science, Finance: University of Washington Press.

Patel V. (2017b) Parents, permission, and possibility: Young women, college, and imagined futures in Gujarat, India. 80: 39-48.

Patrick DJ. (2014) The matter of displacement: a queer urban ecology of New York City's High Line. Social \& Cultural Geography 15: 920-941.

Ramberg L. (2016) Backward Futures and Pasts Forward: Queer Time, Sexual Politics, and Dalit Religiosity in South India. GLQ: A Journal of Lesbian and Gay Studies 22: 223248.

Rogers M. (2008) Modernity,'authenticity', and ambivalence: subaltern masculinities on a South Indian college campus. Journal of the Royal Anthropological Institute 14: 79-95.

Rose G. (2017) Posthuman Agency in the Digitally Mediated City: Exteriorization, Individuation, Reinvention. Annals of the American Association of Geographers 107: 779-793.

Roy AJPT. (2011) Urbanisms, worlding practices and the theory of planning. 10: 6-15.

Roy S. (2016) Breaking the Cage. Dissent Magazine. 
Şahin Ö. (2018) From home to city: gender segregation, homosociality and publicness in Istanbul. Gender, Place \& Culture: 1-15.

Shandilya K. (2015) Nirbhaya's Body: The Politics of Protest in the Aftermath of the 2012 Delhi Gang Rape. Gender \& History 27: 465-486.

Sharma R. (2016) Architecture of intellectual sociality: Tea and coffeehouses in post-colonial Delhi. Mind the Gap: Thinking about in-between spaces in Delhi and Shanghai 7: 275281.

Sheridan D. (2007) The Space of Subculture in the City: GettingSpecific about Berlin's Indeterminate Territories. Field-A Free Journal of Architecture 1: 97-119.

Srinivasan P. (2016) Love Meets Death: "Honour," Violence, and Inter-caste Marriages in Tamil Nadu. In: Nakassis C (ed) Chicago Tamil Forum. University of Chicago: University of Chicago.

Stewart K. (2011) Atmospheric attunements. Environment and Planning D: Society and Space 29: 445-453.

Vacchelli E and Kofman E. (2018) Towards an inclusive and gendered right to the city. 76: 13.

van den Berg M and Chevalier D. (2018) Of "city lounges", "bans on gathering" and macho policies - Gender, class and race in productions of space for Rotterdam's post-industrial future. $76: 36-42$.

Wafer A. (2017) Loitering: reassembling time in the city-of-the-global-south. Social Dynamics 43: 403-420. 